\title{
A Meta-Analysis on the Use of Gabapentinoids for the Treatment of Acute Postoperative Pain Following Total Knee Arthroplasty
}

\author{
Thomas W. Hamilton, BSc, MSc, MBChB, Louise H. Strickland, MSc, BN, and Hemant G. Pandit, FRCS(Orth), DPhil \\ Investigation performed at the Nuffield Department of Orthopaedics, Rheumatology and Musculoskeletal Sciences, \\ University of Oxford, Oxford, United Kingdom
}

\begin{abstract}
Background: Total knee arthroplasty is a painful procedure, with approximately half of patients reporting severe pain during the early postoperative period. Gabapentinoids are used as an adjunct for the management of acute pain in approximately half of enhanced recovery programs. We performed a meta-analysis to assess the effectiveness and safety of gabapentinoids for the treatment of acute postoperative pain following total knee arthroplasty.

Methods: Randomized controlled trials of patients undergoing elective primary total knee arthroplasty that compared the use of the gabapentinoid class of drugs (gabapentin [Neurontin; Pfizer]) or pregabalin [Lyrica; Pfizer]) with that of placebo were retrieved, with 12 studies meeting inclusion criteria. The primary outcome was pain intensity with activity at 48 hours following the surgical procedure. The secondary outcomes included pain intensity at other time points, opioid consumption, knee function, incidence of chronic pain, and adverse events.
\end{abstract}

Results: No difference in pain score at $12,24,48$, or 72 hours following the surgical procedure was seen between gabapentin and placebo. Although pregabalin was associated with reduced pain scores at 24 and 48 hours, this corresponded to a reduction of 0.5 point (95\% confidence interval, 0 to 1.0 point) at 24 hours and 0.3 point (95\% confidence interval, 0 to 0.6 point) at 48 hours on an 11-point numeric rating scale, which was assessed as not clinically important. Overall, no clinically relevant reduction in pain scores was associated with the use of gabapentinoids. Likewise, gabapentinoids were associated with a small, but not clinically important, reduction in cumulative opioid consumption at 48 hours (mean difference, $-23.2 \mathrm{mg}$ [95\% confidence interval, -40.9 to $-5.4 \mathrm{mg}$ ]). There was no difference in knee flexion at 48 hours $(p=0.63)$ or in the incidence of chronic pain at 3 months $(p=0.31)$ or 6 months $(p=0.54)$ associated with the use of gabapentinoids. Although gabapentinoids were associated with a significant reduction in the incidence of nausea (risk ratio, 0.7 [95\% confidence interval, 0.6 to 0.9]; $p<0.001$ ), pregabalin was also associated with a significant, clinically relevant increase in the risk of sedation (risk ratio, 1.4 [95\% confidence interval, 1.1 to 1.9]; $p=0.02$ ).

Conclusions: On the basis of this meta-analysis, we found no evidence to support the routine use of gabapentinoids in the management of acute pain following total knee arthroplasty.

Level of Evidence: Therapeutic Level I. See Instructions for Authors for a complete description of levels of evidence.

Peer Review: This article was reviewed by the Editor-in-Chief and one Deputy Editor, and it underwent blinded review by two or more outside experts. It was also reviewed by an expert in methodology and statistics. The Deputy Editor reviewed each revision of the article, and it underwent a final review by the Editor-in-Chief prior to publication. Final corrections and clarifications occurred during one or more exchanges between the author(s) and copyeditors.

A pproximately half of all patients undergoing total knee arthroplasty experience severe postoperative pain, despite multimodal analgesia ${ }^{1}$. Pain is the most common reason for delayed discharge as well as a common cause of readmission ${ }^{2}$. Improving a patient's perioperative recovery through multimodal enhanced recovery programs has substantial benefits for the patient, surgeon, and health-care payer. Enhanced recovery programs have been demonstrated to reduce short and long-term

Disclosure: One author of this study (T.W.H.) received a grant from the National Institute for Health Research (NIHR) Biomedical Research Unit into Musculoskeletal Disease, Nuffield Orthopaedic Centre and the University of Oxford; funds were used to pay for his time to complete this work. The Disclosure of Potential Conflicts of Interest forms are provided with the online version of the article. 


\section{TABLE I Summary of Included Studies}

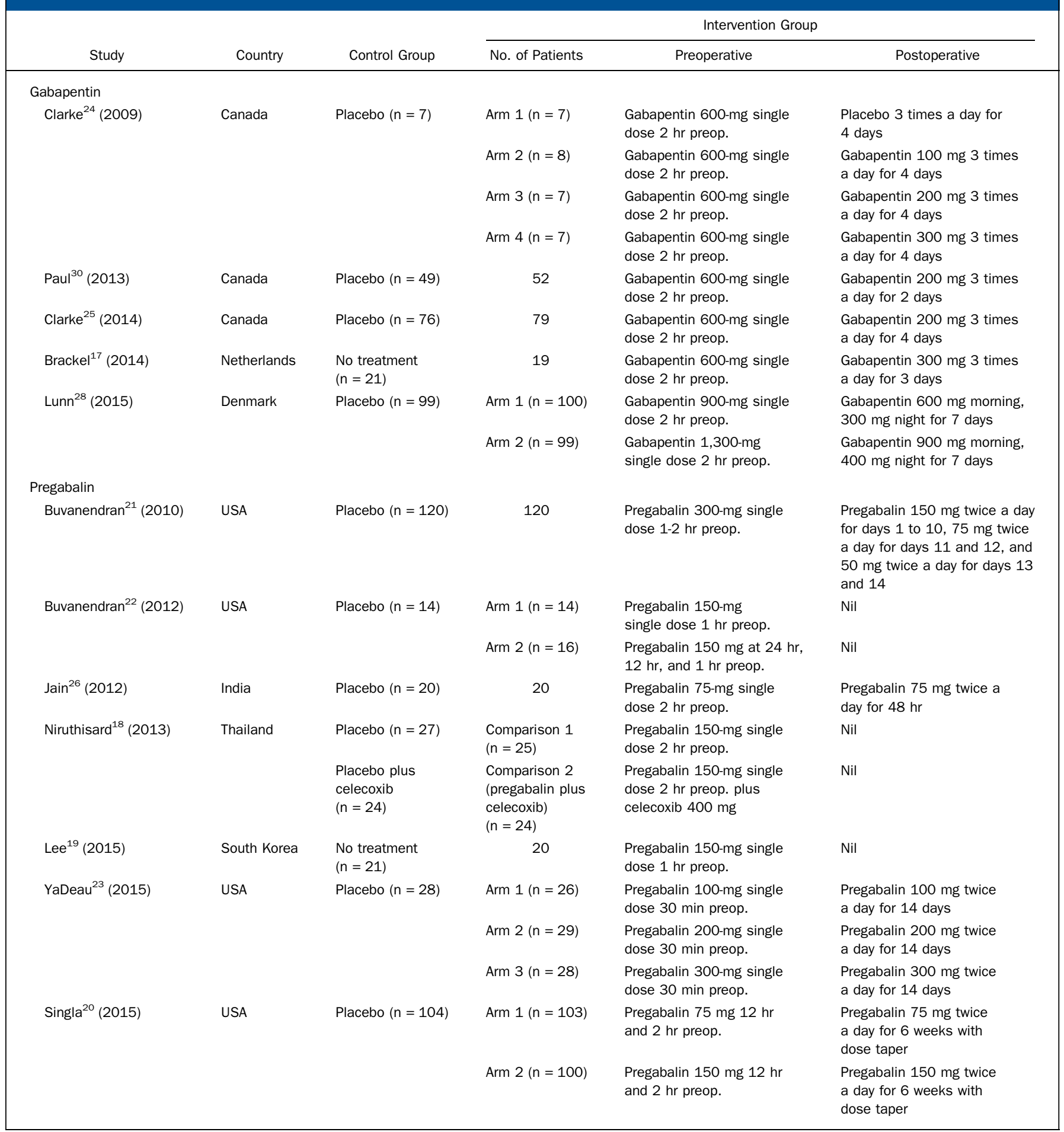

morbidity and mortality, to improve functional outcomes, and to reduce length of stay ${ }^{3-5}$. Although the literature supports the use of enhanced recovery programs, which components of these programs are most important in optimizing patient outcomes in both the short term and the long term remain undefined.
The gabapentinoid class of drugs, which includes gabapentin (Neurontin; Pfizer) and pregabalin (Lyrica; Pfizer), has an established role in the management of neuropathic pain ${ }^{6}$. Although they are not indicated for the management of acute postoperative pain, there is substantial interest in their 
The Journal of Bone \& Joint Surgery $\cdot$ JBjS. Org Volume 98-A · Number 16 -August 17, 2016
Use of Gabapentinoids for Treating acute Postoperative

Pain Following Total Knee Arthroplasty potential as opioid-sparing adjuncts and they are currently used in approximately half of total knee arthroplasty enhanced recovery programs in Great Britain ${ }^{7}$. Gabapentin and pregabalin share a similar chemical structure ${ }^{8}$. They act by inhibiting central nervous system sensitization and, in addition, may inhibit nociceptive transmission in the descending noradrenergic system ${ }^{9,10}$. Although similarities in structure and mechanism exist, pregabalin has an increased potency because of differences in pharmacokinetics and, as such, is associated with an increased clinical efficacy as well as increased prevalence of adverse effects, including sedation and dizziness ${ }^{11}$.

Although previous meta-analyses supported the use of gabapentinoids in reducing acute postoperative pain and limiting opioid use, particularly following abdominal hysterectomy and spinal surgical procedures, to our knowledge, the role of gabapentinoids following total knee arthroplasty has yet to be defined ${ }^{12-15}$. The objective of this current metaanalysis was to determine if gabapentinoids are effective adjuncts in the management of acute postoperative pain following total knee arthroplasty and, if so, whether any benefits seen outweigh the risk of harm posed by drug-related adverse effects.
Materials and Methods

\section{Inclusion and Exclusion Criteria}

$\mathrm{C}$ ligible studies included parallel-group, blinded, randomized controlled trials Cthat involved patients who were $\geq 18$ years of age and were undergoing elective primary total knee arthroplasty and that compared the use of oral gabapentin or pregabalin with that of placebo or no treatment. There was no restriction with respect to studies that investigated single or multiple dosing schedules and preoperative or both preoperative and postoperative dosing, or with respect to the type of anesthesia. The study protocol was registered on the PROSPERO international prospective register of systematic reviews (CRD42015025830).

\section{Information Sources and Search Strategy}

Following Preferred Reporting Items for Systematic Reviews and Meta-Analyses (PRISMA) guidelines, electronic databases (MEDLINE [Ovid], Embase [Ovid], and Web of Science [ISI Web of Knowledge]) were searched from their inception until September 8, 2015 (see Appendix). In addition, reference lists and registers of controlled clinical trials were searched. No restrictions were applied on the basis of the publication status or language.

Studies were assessed, and data were extracted, independently in duplicate. A risk-of-bias assessment was performed on included studies ${ }^{16}$.

\section{Outcome Measures Assessed}

The primary outcome was pain intensity with activity at 48 hours. In cases in which pain with activity at 48 hours was not reported, pain at rest was used if available.

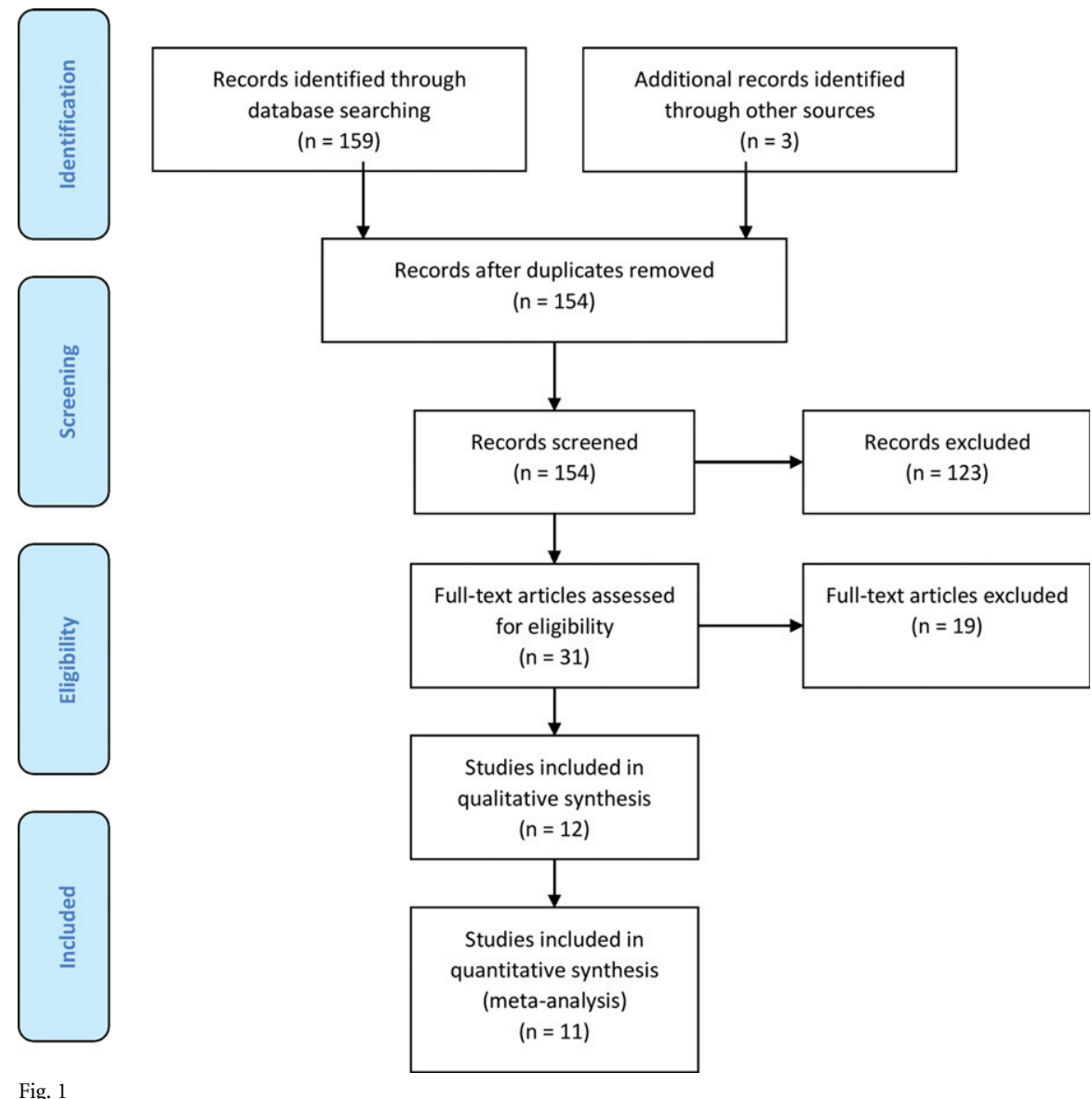

PRISMA flow chart of retrieved studies. 
The Journal of Bone \& Joint Surgery $\cdot$ Jbjs.org Volume 98-A · Number 16 - August 17, 2016
Use of Gabapentinoids for Treating acute Postoperative Pain Following Total Knee Arthroplasty
The secondary outcomes included pain scores at 12, 24, and 72 hours; cumulative opioid consumption ( 0 to 48 hours); active knee flexion at 48 hours; incidence of chronic pain; and adverse events (sedation, dizziness, nausea, and pruritus; 0 to 72 hours). If the incidence of adverse events from 0 to 72 hours was not reported, the incidence at 24 hours was used, as the majority of adverse events occur following the initial loading dose.

\section{Statistical Analysis}

Heterogeneity of data was assessed using the $\mathrm{I}^{2}$ statistic. In cases in which substantial heterogeneity of a data element $\left(\mathrm{I}^{2}>85 \%\right)$ was identified, a metaanalysis was not performed. As a degree of variability was expected, a randomeffects model was used. For continuous data, the standardized mean difference with $95 \%$ confidence interval $(95 \% \mathrm{CI})$ was calculated using the inverse variance method. For opioid consumption, the reported consumption was converted to the oral morphine equivalent dose and the mean difference was calculated. For dichotomous data, the risk ratio was calculated using the Mantel-Haenszel method. Data analysis was performed using Review Manager 5.3 (The Nordic Cochrane Centre, The Cochrane Collaboration). Significance was set at $\mathrm{p}<0.05$.

\section{Results}

Twelve randomized controlled trials compared the use of gabapentin ( 5 studies) or pregabalin (7 studies) with that of placebo, or no treatment, in patients undergoing elective primary total knee arthroplasty (Fig. 1). The results from the study by Brackel et al. were presented in a manner that prevented their inclusion in the quantitative analysis ${ }^{17}$. One study, by Niruthisard et al., was treated as two separate comparisons within the same study because of the combinations of drugs and placebo used ${ }^{18}$. A risk-of-bias assessment is outlined in Figure 2. Lee et al. did not describe the use of placebos or the method of random sequence generation, presenting a high risk of performance bias and an unclear risk of detection and selection bias ${ }^{19}$. Singla et al. did not report information regarding allocation concealment, blinding of participants and personnel, and outcome assessors, presenting an unclear risk of bias ${ }^{20}$. Additionally, only $69 \%$ of participants in that study completed treatment, giving a high risk of attrition bias. Three studies were funded by the manufacturer of the trial drug, presenting an unclear risk of other bias ${ }^{20-22}$. A sensitivity analysis was performed on the basis of the risk of bias, and exclusion of studies at high risk of bias did not change the interpretation of the results.

The dose of gabapentin ranged from 300 to $1,300 \mathrm{mg}$ per day. The dose of pregabalin ranged from 100 to $600 \mathrm{mg}$ per day. The mean patient age ranged from 57 to 68 years, with $43 \%$ to $81 \%$ female participants. The primary indication for total knee arthroplasty was osteoarthritis ( $96 \%$ to $100 \%$ ). A summary of the trials, which included 1,513 knees, is provided in Table I.

Pain Intensity at 48 Hours Following the Surgical Procedure Pain intensity at 48 hours was reported in 8 studies, with a high heterogeneity seen $\left(\mathrm{I}^{2}=73 \%\right)$. At 48 hours, patients receiving gabapentinoids had lower pain scores compared with those receiving placebo (standardized mean difference, -0.15 [95\% CI, -0.28 to -0.02$] ; \mathrm{p}=0.03$ ) (Fig. 3). Subgroup analysis revealed that this effect was limited to patients receiving pregabalin (standardized mean difference, -0.24 [95\% CI, -0.45 to -0.03 ]; $\mathrm{p}=0.03$ ), with no difference seen with patients receiving gabapentin (standardized mean difference, -0.09

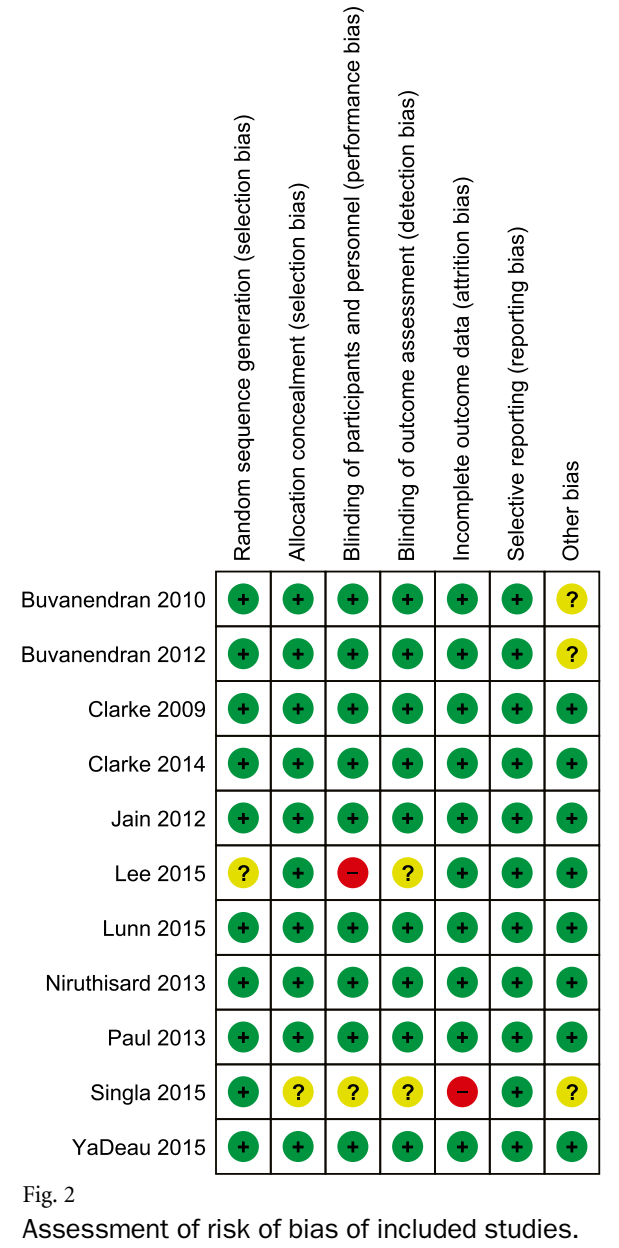

[ $95 \% \mathrm{CI},-0.26$ to 0.08 ]; $\mathrm{p}=0.29$ ). The effect size associated with the use of gabapentinoids was small, and interpreting the standardized mean difference clinically is challenging. On the basis of the mean standard deviation from trials using an 11point numeric rating scale (0 to 10 points), the effect of gabapentinoids corresponds to a reduction of 0.3 point $(95 \% \mathrm{CI}$, 0 to 0.6 point).

These findings were supported by evidence from Brackel et al., who found no difference in pain intensity between those patients who received gabapentin and those who did not ${ }^{17}$. Additionally, Buvanendran et al. found no differences in pain scores from 0 to 32 hours, and YaDeau et al. found no differences at both 24 and 72 hours, in those patients receiving pregabalin ${ }^{22,23}$.

\section{Pain Intensity at Other Time Points Following the Surgical Procedure}

At 12 hours, 4 studies ( 1 on gabapentin and 3 on pregabalin) showed pain scores with activity. High heterogeneity $\left(\mathrm{I}^{2}=\right.$ $88 \%$ ) limited statistical analysis. Clarke et al., assessing gabapentin, found no difference in pain score at 12 hours $^{24}$. Two studies found no significant difference associated with the use of pregabalin ${ }^{20,22}$, and, in 1 small study on 41 knees, Lee et al. reported a positive effect ${ }^{19}$. 
The Journal of Bone \& Joint Surgery • JBjs.org Volume 98-A · Number 16 - August 17, 2016
Use of Gabapentinoids for Treating acute Postoperative Pain Following Total Knee Arthroplasty

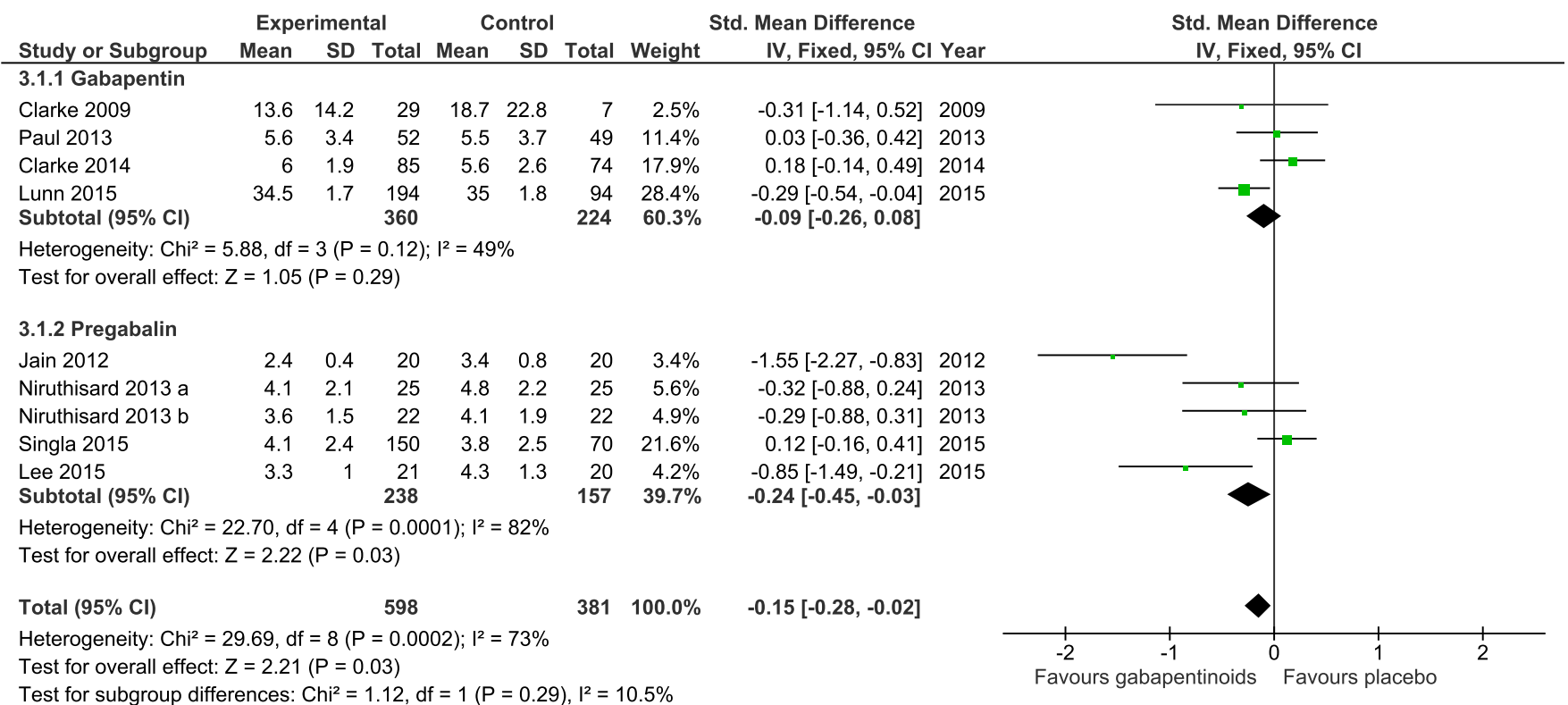

Fig. 3

Pain intensity at 48 hours following the surgical procedure. For the 2013 study by Niruthisard et al. ${ }^{18}$, "a" refers to the patients who did not receive celecoxib and "b" refers to the patients who received celecoxib. SD = standard deviation, IV = inverse variance, and $d f=d e g r e e s$ of freedom.

At 24 hours, pain scores were reported in 10 studies. Subgroup analysis revealed that patients receiving pregabalin had lower 24-hour pain scores (standardized mean difference, -0.30 [95\% CI, -0.58 to -0.01$] ; \mathrm{p}=0.04$ ); however, overall, in patients receiving gabapentinoids, no difference was seen (standardized mean difference, -0.17 [95\% CI, -0.40 to 0.06 ]; $\mathrm{p}=0.14)$ (Fig. 4). On the basis of the mean standard deviation from trials using an 11-point numeric rating scale, the effect of pregabalin corresponded to a reduction of 0.5 point $(95 \% \mathrm{CI}$, 0 to 1.0 point) at 24 hours.

At 72 hours, no difference was seen between patients receiving gabapentinoids (4 studies; standardized mean

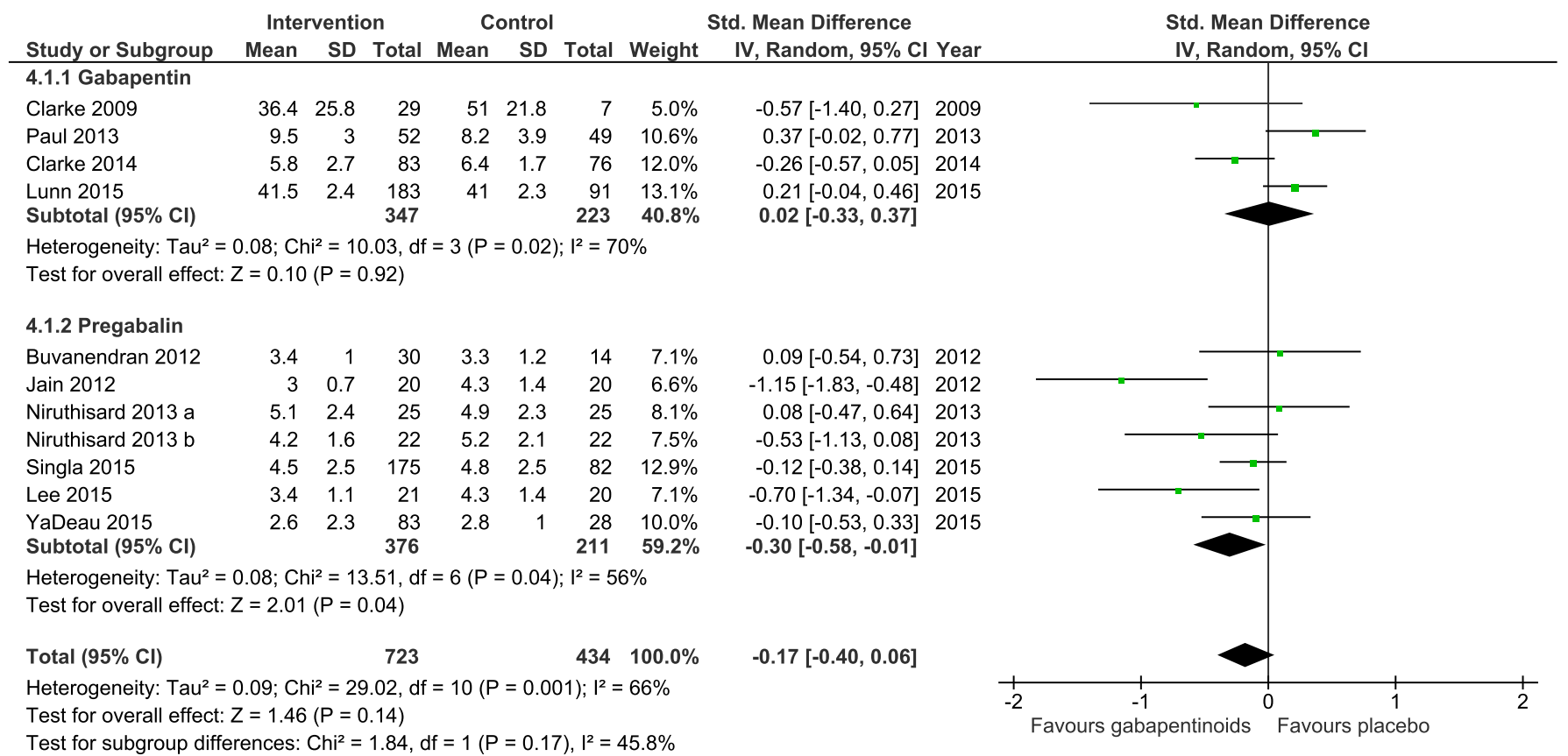

Fig. 4

Pain intensity at 24 hours following the surgical procedure. For the 2013 study by Niruthisard et al. ${ }^{18}$, "a" refers to the patients who did not receive celecoxib and " $b$ " refers to the patients who received celecoxib. SD = standard deviation, IV = inverse variance, and df $=$ degrees of freedom. 
The Journal of Bone \& Joint Surgery $\cdot$ JbjS. org Volume 98-A - Number 16 - August 17, 2016
Use of Gabapentinoids for Treating Acute Postoperative

Pain Following Total Knee Arthroplasty

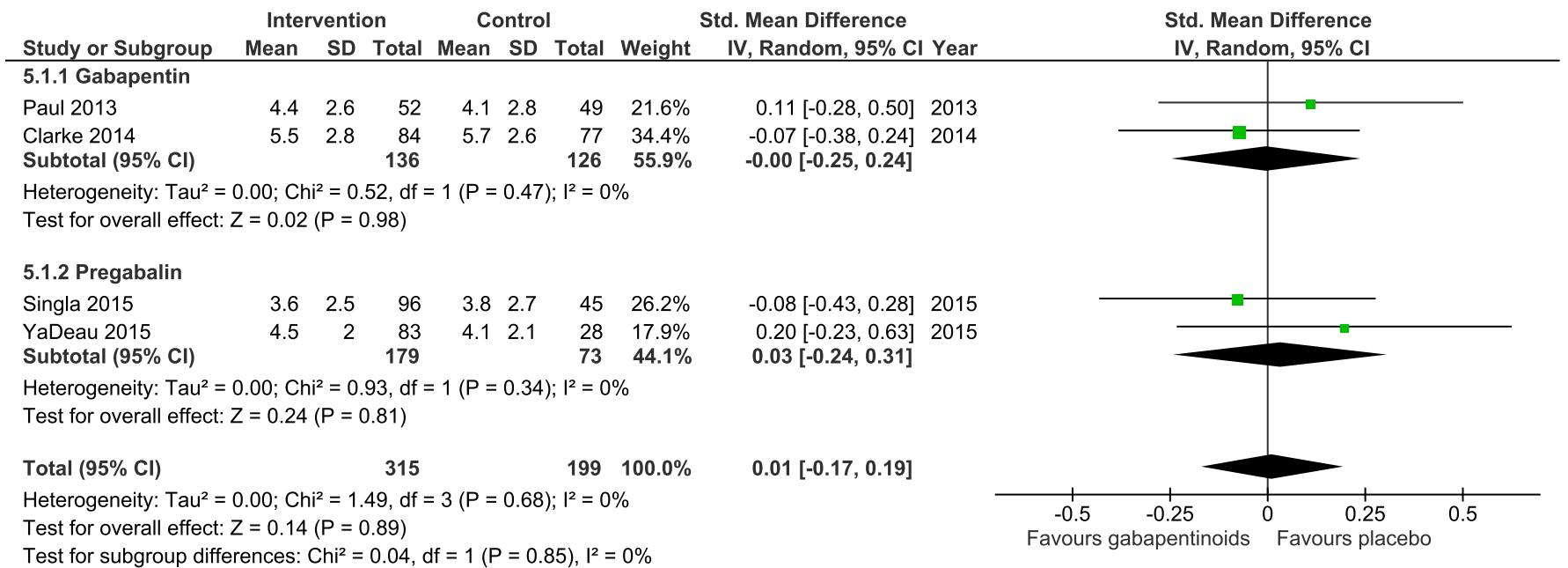

Fig. 5

Pain intensity at 72 hours following the surgical procedure. SD = standard deviation, IV = inverse variance, and df $=$ degrees of freedom.

difference, 0.01 [ $95 \% \mathrm{CI},-0.17$ to 0.19 ]; $\mathrm{p}=0.89$ ) and those receiving placebo; also at 72 hours, there was no difference seen on a subgroup analysis of patients receiving gabapentin or pregabalin compared with those receiving placebo (Fig. 5).

\section{Cumulative Opioid Consumption at 48 Hours Following the Surgical Procedure}

Patients receiving gabapentinoids had lower cumulative opioid consumption (6 studies) compared with those receiving placebo (mean difference, $-23.19 \mathrm{mg}$ [ $95 \% \mathrm{CI},-40.93$ to $-5.44 \mathrm{mg}$ ]; $\mathrm{p}=0.01$ ) (Fig. 6). Subgroup analysis revealed that this effect was limited to pregabalin (mean difference, $-33.14 \mathrm{mg}[95 \% \mathrm{CI}$,
-53.98 to $-12.29 \mathrm{mg}] ; \mathrm{p}=0.002)$, with no difference seen with gabapentin (mean difference, $-6.66 \mathrm{mg}$ [95\% CI, -23.78 to $10.47 \mathrm{mg}] ; \mathrm{p}=0.45)$.

However, Brackel et al. found no difference in those receiving gabapentin, and Clarke et al. found a $10-\mathrm{mg}$ reduction in 24-hour cumulative opioid consumption associated with the use of gabapentin ${ }^{17,25}$. Buvanendran et al. and Jain et al. reported similar reductions in 24-hour opioid consumption associated with pregabalin ${ }^{21,26}$. The clinical relevance of these reductions was not discussed in any studies, but, overall, the reduction associated with pregabalin was small, corresponding to a $15 \%$ reduction in opioid consumption.

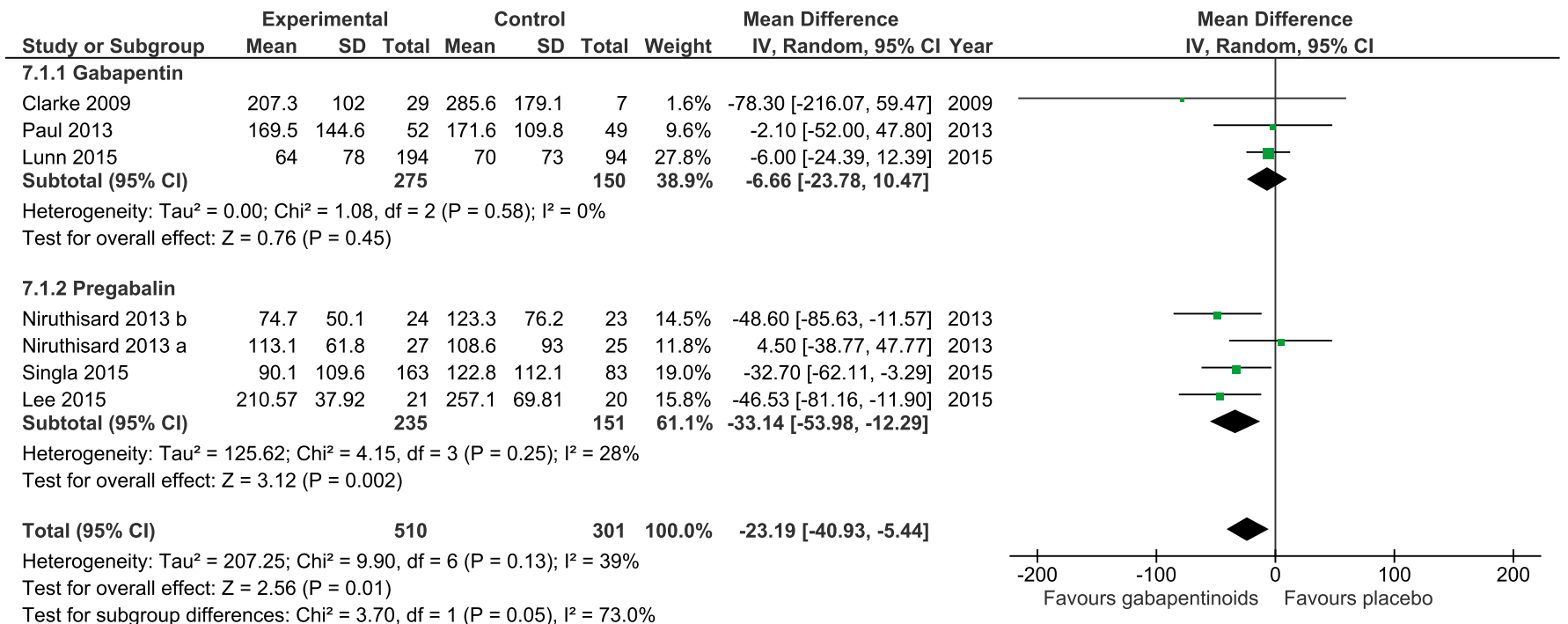

Fig. 6

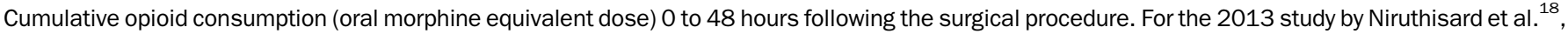

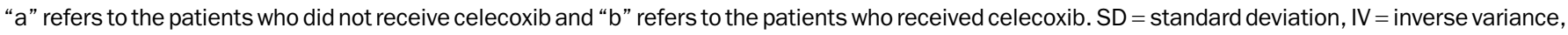
and $\mathrm{df}=$ degrees of freedom. 


\section{Functional Outcomes}

Active knee flexion at 48 hours was reported in 5 studies, with no difference seen in patients receiving gabapentinoids (mean difference, $1.10^{\circ}\left[95 \% \mathrm{CI},-3.41^{\circ}\right.$ to $\left.5.62^{\circ}\right] ; \mathrm{p}=0.63$ ) or on subgroup analysis.

Three studies investigated the incidence of chronic pain following perioperative pregabalin. YaDeau et $\mathrm{al}^{23}$ and Buvanendran et al..$^{21}$ reported the incidence of neuropathic pain assessed using the Leeds Assessment of Neuropathic Symptoms and Signs (LANSS) pain scale ${ }^{27}$. Singla et al. reported the incidence of pain using an 11-point numeric rating scale where a score of $\geq 1$ was regarded as positive ${ }^{20}$. At both 3 months (risk ratio, 0.43 [95\% CI, 0.09 to 2.15]; $\mathrm{p}=$ 0.31 ) and 6 months (risk ratio, 0.43 [95\% CI, 0.03 to 6.69]; $\mathrm{p}=0.54$ ), no difference in the incidence of pain was seen between patients receiving pregabalin and those receiving placebo (Fig. 7).

\section{Adverse Effects}

No increase in the risk of sedation (5 studies) was observed in those patients receiving gabapentinoids (risk ratio, $1.19[95 \%$ CI, 0.90 to 1.56]; $p=0.22$ ) (Fig. 8). Subgroup analysis revealed that, although in those studies assessing gabapentin, no difference was seen (risk ratio, 0.95 [95\% CI, 0.76 to 1.20]; $\mathrm{p}=$ 0.68 ), in those studies in which the patients received pregabalin, an increased incidence of sedation was observed (risk ratio, 1.44 [95\% CI, 1.07 to 1.94$] ; \mathrm{p}=0.02$ ). The number needed to treat with pregabalin to result in 1 case of sedation was 8.7.

These data were supported by evidence from Clarke et al., who found no difference in sedation associated with the use of gabapentin at any time points ${ }^{25}$. Additionally, al- though Lunn et al. found an increased incidence of sedation at 6 hours, following a loading dose of 900-mg gabapentin, there was no difference in sedation seen at any other time points $^{28}$.

No difference in the incidence of dizziness ( 6 studies) was seen in patients receiving gabapentinoids (risk ratio, 1.15 [95\% CI, 0.81 to 1.62 ]; $\mathrm{p}=0.43$ ) or on subgroup analysis ${ }^{20,21,25,26,29,30}$.

There was a decreased risk of nausea (7 studies) associated with the use of gabapentinoids (risk ratio, 0.74 [95\% CI, 0.63 to 0.88 ]; $p<0.001$ ) (Fig. 9). Subgroup analysis revealed that this finding was seen in those studies assessing gabapentin (risk ratio, 0.80 [95\% CI, 0.65 to 0.97]; $\mathrm{p}=0.03$ ) but not in those assessing pregabalin (risk ratio, 0.72 [95\% CI, 0.50 to 1.03 ]; $\mathrm{p}=0.07$ ), in which the difference in the risk of nausea compared with that in patients receiving placebo did not reach significance. The number needed to treat with gabapentin to result in 1 fewer case of nausea was 9.7.

No difference in the incidence of pruritus ( 5 studies) was seen in patients receiving gabapentinoids (risk ratio, 0.69 [95\% CI, 0.39 to 1.22$] ; \mathrm{p}=0.20$ ) or on subgroup analysis ${ }^{21,24-27,30}$.

\section{Effect of Dose}

Subgroup analysis was performed to investigate the impact of gabapentinoid dose. At 48 hours, high-dose gabapentin ( $\geq 900 \mathrm{mg} /$ day; 3 trial arms, 206 participants) was associated with lower pain scores (standardized mean difference, -0.30 [ $95 \% \mathrm{CI},-0.54$ to -0.05$]$ ) compared with both control patients $(\mathrm{p}=0.02)$ and patients receiving low-dose gabapentin $(<900 \mathrm{mg} /$ day; 5 trial arms, 153 participants; $\mathrm{p}=0.02)$, which was not associated with any difference in pain scores (standardized mean difference, 0.10 [ $95 \% \mathrm{CI},-0.14$ to 0.34$]$ ). The effect of high-dose gabapentin corresponds to a reduction of 
The Journal of Bone \& Joint Surgery $\cdot$ JBjS. Org Volume 98 -A - Number 16 - August 17, 2016
Use of Gabapentinoids for Treating acute Postoperative Pain Following Total Knee arthroplasty

Experimental Control Risk Ratio

Study or Subgroup

Events Total Events Total Weight

M-H, Random, $95 \% \mathrm{Cl}$

Risk Ratio

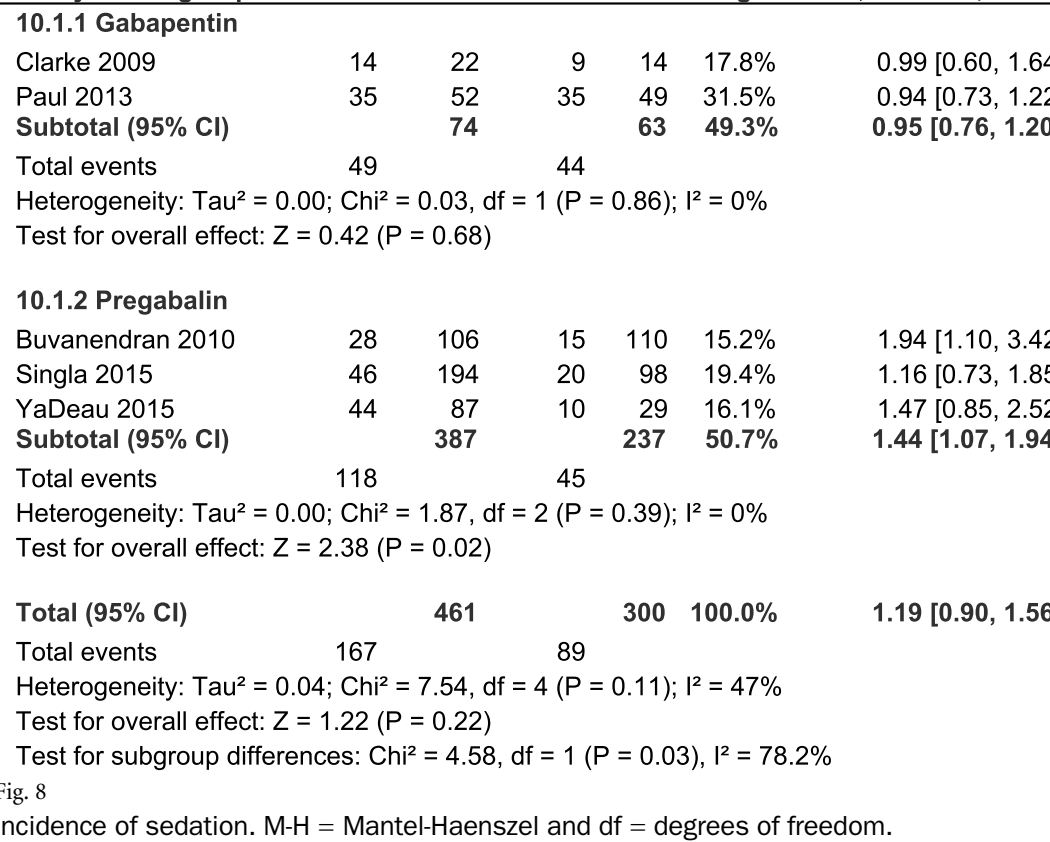

M-H, Random, $95 \% \mathrm{CI}$

0.4 point (95\% CI, 0 to 0.7 point) on an 11-point numeric rating scale and, as such, was not assessed as clinically relevant. No difference was seen between different doses with respect to the pain score at other time points or cumulative opioid intake. No difference in pain outcome scores or opioid consumption was detected between low-dose pregabalin (<300 mg/day; 8 arms, 248 participants) and high-dose pregabalin ( $\geq 300 \mathrm{mg} / \mathrm{day} ; 4$ arms, 277 participants). It was not possible to assess the impact of dose on the risk of adverse events for gabapentin or pregabalin.

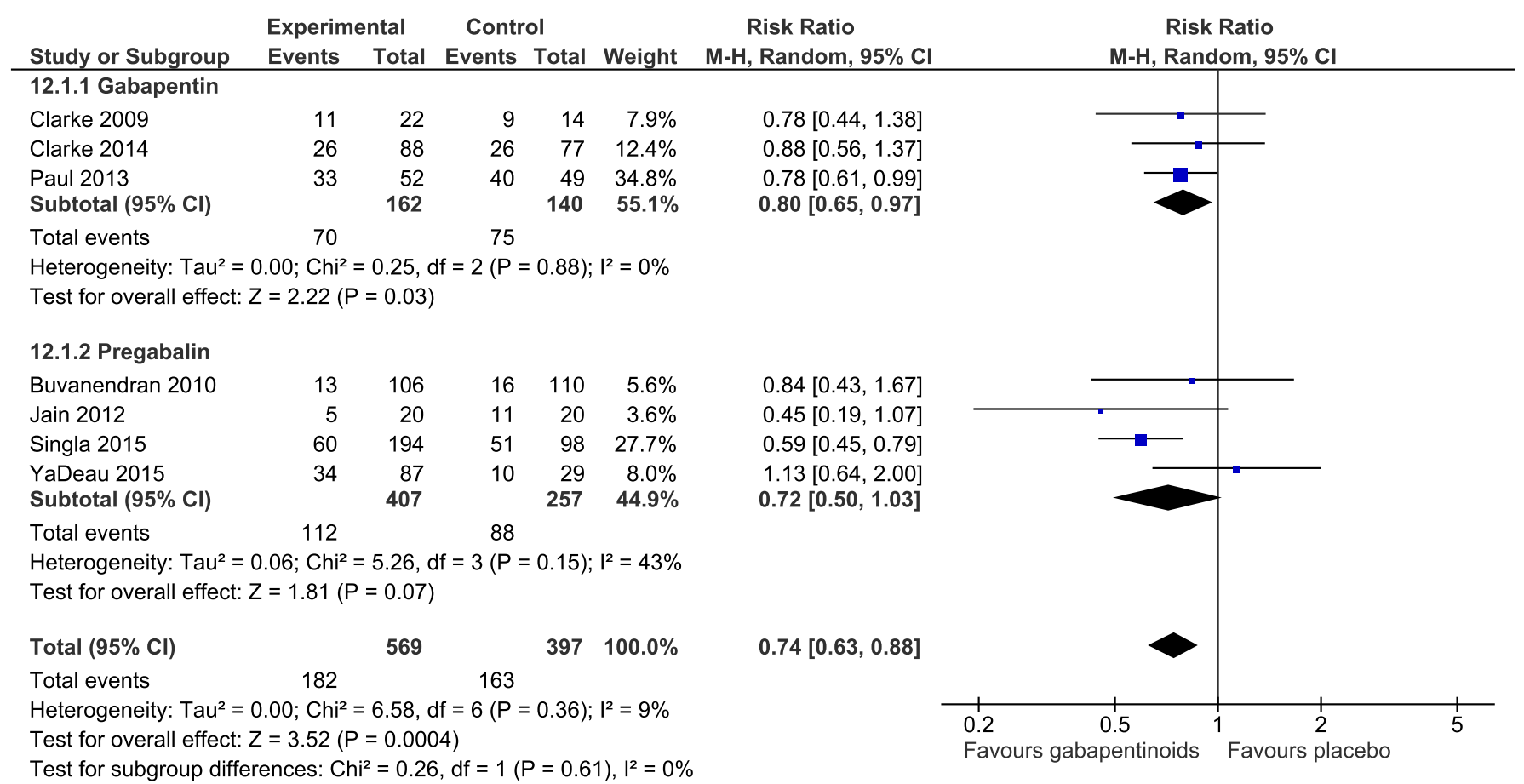

Fig. 9

Incidence of nausea. $\mathrm{M}-\mathrm{H}=$ Mantel-Haenszel and $\mathrm{df}=$ degrees of freedom. 
The Journal of Bone \& Joint Surgery · Jbjs.org Volume 98-A • Number $16 \cdot$ August 17, 2016
Use of Gabapentinoids for Treating acute Postoperative Pain Following Total Knee Arthroplasty

\section{Discussion}

$\mathrm{O}$ ur meta-analysis has demonstrated that the use of gabapentin is not associated with reduced pain scores at 12, 24, 48 , or 72 hours. Although subgroup analysis revealed that pregabalin is associated with a reduction in pain scores, equivalent on an 11-point numeric rating scale to 0.5 point $(95 \% \mathrm{CI}$, 0 to 1.0 point) at 24 hours and 0.3 point ( $95 \%$ CI, 0 to 0.6 point) at 48 hours, this reduction is not of clinical importance. Overall, no clinically relevant reduction in pain scores was associated with the use of gabapentinoids at any of the time points. Gabapentinoids were associated with a reduction in cumulative opioid consumption, although this effect was found to be small (15\%) and likely not of clinical importance. There was no evidence that the use of gabapentinoids improved short or longterm function, with no difference in knee flexion at 48 hours or incidence of chronic pain at 3 or 6 months. Gabapentinoids were associated with a reduction in the incidence of nausea but pregabalin was associated with a clinically relevant increase in sedation. To our knowledge, this is the first meta-analysis to assess the efficacy of gabapentinoids in the management of acute postoperative pain following total knee arthroplasty. We have found no evidence to support the routine use of gabapentinoids in the management of acute pain following total knee arthroplasty, and this study does not support the routine use of gabapentinoids as part of an enhanced recovery program.

The results of this study are contradictory to previous meta-analyses assessing the use of gabapentinoids in the management of acute non-extremity post-surgical pain that have found that their use was associated with significant reductions in pain following tonsillectomy, abdominal hysterectomy, and thoracic and spinal surgical procedures ${ }^{31-36}$. Possible explanations for these differences include differences in the mechanism and response to pain at different surgical sites that may be due to disease factors, surgical factors, or patient factors including patient selection and central sensitization. In their meta-analysis, Mishriky et al. found that the type of surgical procedure was a significant predictor of postoperative pain scores, accounting for $32 \%$ of the variance at 24 hours $^{15}$. Eipe et al. proposed that gabapentinoids are most likely to demonstrate efficacy in conditions associated with chronic pain, including spinal surgical procedures, amputations, and joint arthroplasty ${ }^{14,37}$. Although chronic pain is seen in approximately $20 \%$ of patients following total knee arthroplasty, this figure is lower than the $32 \%$ following discectomy and up to $85 \%$ seen following amputation ${ }^{38-40}$. If the mechanism proposed by Eipe et al. is correct, then the lower incidence of chronic pain observed following total knee arthroplasty, compared with other surgical procedures, may explain why gabapentinoids failed to demonstrate efficacy in this population.

The use of pregabalin was associated with a reduction of $33 \mathrm{mg}$ (95\% CI, 12 to $54 \mathrm{mg}$ ) (a $15 \%$ reduction) in the oral morphine equivalent dose over 48 hours following total knee arthroplasty, with this finding unlikely to be of clinical relevance in this population because of the high baseline opioid consumption $^{12,15}$. Although a reduction in the incidence of postoperative nausea following total knee arthroplasty was associated with gabapentinoids, this effect was limited to gabapentin (number needed to treat $=10$ ), with no reduction seen with pregabalin. As such, this anti-emetic effect is unlikely to be due to reduced opioid consumption and is likely to be via alternative mechanisms ${ }^{41}$. Furthermore, no differences in other opioid-related adverse effects, including pruritus or dizziness, were seen, providing further evidence that the reduction in opioid consumption may not be of clinical relevance. One adverse effect that was noted to increase following the administration of pregabalin, but not gabapentin, was the risk of sedation (number needed to treat $=$ 9). It has been reported previously that the risk of sedation increases with increasing dose, and the incidence is known to be higher following the first dose; however, it was not possible to evaluate these factors in the published studies. Although there is evidence that gabapentinoids improves sleep quality and patient satisfaction following total knee arthroplasty ${ }^{22,28,42,43}$, sedation may prevent early mobilization following the surgical procedure, and early mobilization has a strong evidence base in this population.

It has previously been reported that the use of gabapentinoids may be associated with a reduction in the incidence of chronic pain ${ }^{44}$. The current meta-analysis found no evidence of improved short-term knee function or reduction in knee pain at 3 or 6 months. Interestingly, the only study that showed lower pain scores at 3 and 6 months had a higher baseline incidence of chronic pain at $9 \%$ compared with $4 \%$ seen in another study using the same outcome measure (LANSS) $)^{21,23}$. Although the lack of data prevents formal analysis, it is interesting to note that the baseline incidence of chronic pain in a meta-analysis showing a reduction in chronic pain associated with gabapentinoids was $25 \%$ (range, $5 \%$ to $82 \%$ ) $^{44}$. Because the current evidence does not support the routine use of gabapentinoids to reduce chronic pain, further work is required to explore if gabapentinoids have a role in subgroups of patients undergoing total knee arthroplasty and at high risk of this complication.

The limitations of the current meta-analysis were that there were insufficient studies to permit evaluation of different dose regimens, timings, and frequency of gabapentinoids, and that, due to different anesthetic and perioperative analgesic regimes as well as patient differences, significant heterogeneity was observed among studies. Although the level of heterogeneity was below prespecified levels to perform meta-analysis, further studies would have enhanced the strength of the evidence presented. The strengths of this study are that it includes a large number of knees from high-quality clinical trials at a low risk of bias.

In summary, based on our meta-analysis, we found no evidence to support the routine use of gabapentinoids in the management of acute postoperative pain following total knee arthroplasty. Although some analgesic efficacy and opioidsparing effects were seen with the use of pregabalin, these were unlikely to be of clinical importance. Additionally, no beneficial effects in improving short-term function or reducing the longterm incidence of chronic pain were detected and, although an anti-emetic effect was observed, a significant increase in the risk of sedation associated with the use of pregabalin was detected. Further high-quality randomized controlled trials, in particular those investigating patients at high risk of chronic 
The Journal of Bone \& Joint Surgery $\cdot$ JBjS. Org Volume 98-A · Number 16 - August 17, 2016
Use of Gabapentinoids for Treating Acute Postoperative Pain Following Total Knee Arthroplasty pain, may yield positive results in subgroups of patients; however, the current evidence does not support the routine use of gabapentinoids as part of an enhanced recovery program for total knee arthroplasty.

\section{Appendix}

eA Text showing the MEDLINE (Ovid) search strategy used article as a data supplement at jbjs.org.
Thomas W. Hamilton, BSc, MSc, $\mathrm{MBChB}^{1}$

Louise H. Strickland, MSc, BN ${ }^{1}$

Hemant G. Pandit, FRCS(Orth), DPhil ${ }^{1,2}$

${ }^{1}$ Nuffield Department of Orthopaedics, Rheumatology and Musculoskeletal Sciences, University of Oxford, Oxford, United Kingdom

${ }^{2}$ Nuffield Orthopaedic Centre, Oxford, United Kingdom

E-mail address for T.W. Hamilton: thomas.hamilton@ndorms.ox.ac.uk

\section{References}

1. Chan EY, Blyth FM, Cheow SL, Fransen M. Postoperative pain following hospital discharge after knee replacement surgery: a patient survey. Pain Manag. 2013 May;3(3):177-88. Epub 2014 Mar 25.

2. Husted H, Lunn TH, Troelsen A, Gaarn-Larsen L, Kristensen BB, Kehlet H. Why still in hospital after fast-track hip and knee arthroplasty? Acta Orthop. 2011 Dec;82 (6):679-84. Epub 2011 Nov 9.

3. Ibrahim MS, Khan MA, Nizam I, Haddad FS. Peri-operative interventions producing better functional outcomes and enhanced recovery following total hip and knee arthroplasty: an evidence-based review. BMC Med. 2013 Feb 13;11:37.

4. Savaridas T, Serrano-Pedraza I, Khan SK, Martin K, Malviya A, Reed MR. Reduced medium-term mortality following primary total hip and knee arthroplasty with an enhanced recovery program. A study of 4,500 consecutive procedures. Acta Orthop. 2013 Feb;84(1):40-3. Epub 2013 Jan 31.

5. Paton F, Chambers D, Wilson P, Eastwood A, Craig D, Fox D, Jayne D, McGinnes E. Effectiveness and implementation of enhanced recovery after surgery programmes: a rapid evidence synthesis. BMJ Open. 2014 Jul 22;4(7):e005015.

6. Wiffen PJ, McQuay HJ, Edwards JE, Moore RA. Gabapentin for acute and chronic pain. Cochrane Database Syst Rev. 2005 Jul 20;3:CD005452.

7. Nagra N, Hamilton TW, Murray DW, Pandit HG. Inconsistencies in the enhanced recovery programmes across the NHS. Telford, UK: British Association for Surgery of the Knee; 2015.

8. Bockbrader HN, Wesche D, Miller R, Chapel S, Janiczek N, Burger P. A comparison of the pharmacokinetics and pharmacodynamics of pregabalin and gabapentin. Clin Pharmacokinet. 2010 Oct;49(10):661-9.

9. Weinbroum AA. Non-opioid IV adjuvants in the perioperative period: pharmacological and clinical aspects of ketamine and gabapentinoids. Pharmacol Res. 2012 Apr;65(4):411-29. Epub 2012 Jan 30.

10. Hayashida K, DeGoes S, Curry R, Eisenach JC. Gabapentin activates spinal noradrenergic activity in rats and humans and reduces hypersensitivity after surgery. Anesthesiology. 2007 Mar;106(3):557-62.

11. Schmidt PC, Ruchelli G, Mackey SC, Carroll IR. Perioperative gabapentinoids: choice of agent, dose, timing, and effects on chronic postsurgical pain. Anesthesiology. 2013 Nov;119(5):1215-21. Epub 2013 Sep 21.

12. Zhang J, Ho KY, Wang Y. Efficacy of pregabalin in acute postoperative pain: a meta-analysis. Br J Anaesth. 2011 Apr;106(4):454-62. Epub 2011 Feb 26. 13. Straube S, Derry S, Moore RA, Wiffen PJ, McQuay HJ. Single dose oral gabapentin for established acute postoperative pain in adults. Cochrane Database Syst Rev. 2010 May 12;5:CD008183.

14. Eipe N, Penning J, Yazdi F, Mallick R, Turner L, Ahmadzai N, Ansari MT. Perioperative use of pregabalin for acute pain-a systematic review and meta-analysis. Pain. 2015 Jul;156(7):1284-300. Epub 2015 Apr 2.

15. Mishriky BM, Waldron NH, Habib AS. Impact of pregabalin on acute and persistent postoperative pain: a systematic review and meta-analysis. Br J Anaesth. 2015 Jan;114(1):10-31. Epub 2014 Sep 10.

16. Higgins JP, Altman DG, Gøtzsche PC, Jüni $P$, Moher D, Oxman AD, Savovic J, Schulz KF, Weeks L, Sterne JA; Cochrane Bias Methods Group; Cochrane Statistical Methods Group. The Cochrane Collaboration's tool for assessing risk of bias in randomised trials. BMJ. 2011 Oct 18:343:d5928.

17. Brackel AML, Marting LN, Timmerman L. Comparison of local infiltration analgesia with epidural analgesia after total knee arthroplasty: a randomized clinical trial (NCT01489631). Zeist: Dutch Society of Anesthesiology; 2014 Sep.

18. Niruthisard $S$, Earsakul $A$, Bunburaphong $P$, Chinda $P$, Anutinmanee $R$, Prapreuttham S, Tunprayoon A, Werawatganon T. Preoperative pregabalin and/or celecoxib for pain management after total knee arthroplasty under intrathecal morphine: a randomized controlled trial. Asian Biomedicine. 2013 Aug; 7(4): $579-85$

19. Lee JK, Chung KS, Choi $\mathrm{CH}$. The effect of a single dose of preemptive pregabalin administered with COX-2 inhibitor: a trial in total knee arthroplasty. J Arthroplasty. 2015 Jan;30(1):38-42. Epub 2014 Apr 13.
20. Singla NK, Chelly JE, Lionberger DR, Gimbel J, Sanin L, Sporn J, Yang R, Cheung $\mathrm{R}$, Knapp L, Parsons B. Pregabalin for the treatment of postoperative pain: results from three controlled trials using different surgical models. J Pain Res. 2015;8:9-20. Epub 2014 Dec 23.

21. Buvanendran A, Kroin JS, Della Valle CJ, Kari M, Moric M, Tuman KJ. Perioperative oral pregabalin reduces chronic pain after total knee arthroplasty: a prospective, randomized, controlled trial. Anesth Analg. 2010 Jan 1;110(1):199-207. Epub 2009 Nov 12

22. Buvanendran A, Kroin JS, Della Valle CJ, Moric M, Tuman KJ. Cerebrospinal fluid neurotransmitter changes during the perioperative period in patients undergoing total knee replacement: a randomized trial. Anesth Analg. 2012 Feb;114(2):434-41. Epub 2011 Dec 9.

23. YaDeau JT, Lin Y, Mayman DJ, Goytizolo EA, Alexiades MM, Padgett DE, Kahn RL, Jules-Elysee KM, Ranawat AS, Bhagat DD, Fields KG, Goon AK, Curren J, Westrich GH. Pregabalin and pain after total knee arthroplasty: a double-blind, randomized, placebo-controlled, multidose trial. Br J Anaesth. 2015 Aug;115(2):28593. Epub 2015 Jul 15.

24. Clarke H, Pereira S, Kennedy D, Gilron I, Katz J, Gollish J, Kay J. Gabapentin decreases morphine consumption and improves functional recovery following total knee arthroplasty. Pain Res Manag. 2009 May-Jun; 14(3):217-22.

25. Clarke HA, Katz J, McCartney CJ, Stratford P, Kennedy D, Pagé MG, Awad IT, Gollish J, Kay J. Perioperative gabapentin reduces $24 \mathrm{~h}$ opioid consumption and improves in-hospital rehabilitation but not post-discharge outcomes after total knee arthroplasty with peripheral nerve block. Br J Anaesth. 2014 Nov;113(5):855-64. Epub 2014 Jun 30.

26. Jain P, Jolly A, Bholla V, Adatia S, Sood J. Evaluation of efficacy of oral pregabalin in reducing postoperative pain in patients undergoing total knee arthroplasty. Indian J Orthop. 2012 Nov;46(6):646-52. Epub 2013 Jan 18.

27. Bennett $M$. The LANSS Pain Scale: the Leeds assessment of neuropathic symptoms and signs. Pain. 2001 May;92(1-2):147-57. Epub 2001 Apr 27. 28. Lunn TH, Husted H, Laursen MB, Hansen LT, Kehlet H. Analgesic and sedative effects of perioperative gabapentin in total knee arthroplasty: a randomized, double-blind, placebo-controlled dose-finding study. Pain. 2015 Dec; 156(12):2438-48.

29. Clarke H, Pereira S, Kennedy D, Andrion J, Mitsakakis N, Gollish J, Katz J, Kay J. Adding gabapentin to a multimodal regimen does not reduce acute pain, opioid consumption or chronic pain after total hip arthroplasty. Acta Anaesthesiol Scand. 2009 Sep;53(8):1073-83. Epub 2009 Jun 30.

30. Paul JE, Nantha-Aree M, Buckley N, Cheng J, Thabane L, Tidy A, DeBeer J, Winemaker M, Wismer D, Punthakee D, Avram V. Gabapentin does not improve multimodal analgesia outcomes for total knee arthroplasty: a randomized controlled trial. Can J Anaesth. 2013 May;60(5):423-31. Epub 2013 Mar 12.

31. Hwang SH, Park IJ, Cho YJ, Jeong YM, Kang JM. The efficacy of gabapentin/ pregabalin in improving pain after tonsillectomy: a meta-analysis. Laryngoscope. 2016 Feb;126(2):357-66. Epub 2015 Sep 25.

32. Alayed N, Alghanaim N, Tan X, Tulandi T. Preemptive use of gabapentin in abdominal hysterectomy: a systematic review and meta-analysis. Obstet Gynecol. 2014 Jun;123(6):1221-9. Epub 2014 May 9.

33. Yu L, Ran B, Li M, Shi Z. Gabapentin and pregabalin in the management of postoperative pain after lumbar spinal surgery: a systematic review and metaanalysis. Spine (Phila Pa 1976). 2013 Oct 15;38(22):1947-52. Epub 2013 Aug 8.

34. Zakkar M, Frazer S, Hunt I. Is there a role for gabapentin in preventing or treating pain following thoracic surgery? Interact Cardiovasc Thorac Surg. 2013 Oct;17 (4):716-9. Epub 2013 Jul 6.

35. Mathiesen O, Møiniche S, Dahl JB. Gabapentin and postoperative pain: a qualitative and quantitative systematic review, with focus on procedure. BMC Anesthesiol. 2007 Jul 7;7:6. 


\section{0}

The Journal of Bone \& Joint Surgery $\cdot$ JBjs.org Volume 98-A · Number $16 \cdot$ August 17, 2016

36. Yao Z, Shen C, Zhong Y. Perioperative pregabalin for acute pain after gynecological surgery: a meta-analysis. Clin Ther. 2015 May 1;37(5):1128-35. Epub 2014 Jun 2.

37. Eipe N, Penning J, Ansari M, Yazdi F, Ahmadzai N. A protocol for a systematic review for perioperative pregabalin use. Syst Rev. 2012 Sep 13;1:40.

38. Beswick AD, Wylde V, Gooberman-Hill R, Blom A, Dieppe P. What proportion of patients report long-term pain after total hip or knee replacement for osteoarthritis? A systematic review of prospective studies in unselected patients. BMJ Open. 2012 Feb 22;2(1):e000435

39. Parker SL, Xu R, McGirt MJ, Witham TF, Long DM, Bydon A. Long-term back pain after a single-level discectomy for radiculopathy: incidence and health care cost analysis. J Neurosurg Spine. 2010 Feb;12(2):178-82.

40. Hsu E, Cohen SP. Postamputation pain: epidemiology, mechanisms, and treatment. J Pain Res. 2013;6:121-36. Epub 2013 Feb 13.
Use of Gabapentinoids for Treating Acute Postoperative Pain Following Total Knee Arthroplasty

1. Kong VK, Irwin MG. Gabapentin: a multimodal perioperative drug? Br J Anaesth. 2007 Dec;99(6):775-86. Epub 2007 Nov 17.

42. Gong $L$, Wang $Z$, Fan $D$. Sleep quality effects recovery after total knee arthroplasty (TKA) - a randomized, double-blind, controlled study. J Arthroplasty. 2015 Nov;30(11):1897-901. Epub 2015 Feb 24.

43. den Hertog A, Gliesche K, Timm J, Mühlbauer B, Zebrowski S. Pathwaycontrolled fast-track rehabilitation after total knee arthroplasty: a randomized prospective clinical study evaluating the recovery pattern, drug consumption, and length of stay. Arch Orthop Trauma Surg. 2012 Aug;132(8):1153-63. Epub 2012 May 27.

44. Clarke H, Bonin RP, Orser BA, Englesakis M, Wijeysundera DN, Katz J. The prevention of chronic postsurgical pain using gabapentin and pregabalin: a combined systematic review and meta-analysis. Anesth Analg. 2012 Aug;115(2):42842. Epub 2012 Mar 13 